Uludag Univ. J. Fac. Vet. Med.

35 (2016), 1,2: 61-64

\title{
Kıvırcık Irkı Bir Kuzuda Meningosel ve Unilateral Serebellar Hipoplazi
}

\author{
İsmail Altuğ ŞEN ${ }^{1} \quad$ Volkan İPEK ${ }^{2} \quad$ Aylin Alasonyalılar DEMİRER ${ }^{2}$ \\ Hakan SALCI ${ }^{1}$
}

Özet: Bu olgu bir kuzuda meningosel ile birlikte şekillenmiş unilateral serebellar hipoplazi patolojisine ait ilk rapordur. İki günlük Kıvırcık ırkı, erkek bir kuzu doğuştan başın arka kısmında şişkinlik, ayağa kalkamama ve kafasını toparlayamama şikayetleriyle getirildi. Klinik olarak anamnezde belirtilen bulguların yanında, oksipital bölgede $6 \mathrm{~cm}$ çapl, ağrısız ve fluktuasyon gösteren derisiz şişkinlik belirlendi. Genel anestezi altında şişkinliğin ekstirpasyonu yapıldı. Postoperatif yakın dönem iyileşme gözlenmediği için olgu ötenazi edildi. Nekropsi ve histopatolojik incelemeler neticesinde meningosel ve unilateral serebellar hipoplazi tanısı konuldu.

Anahtar Kelimeler: Meningosel, unilateral serebellar hipoplazi, kuzu.

\section{Meningocel and Unilateral Cerebellar Hypoplasi in a Kıvırcık Breed Lamb}

\begin{abstract}
This is the first report pertain to unilateral cerebellar hypoplasia pathology together with meningocel in a lamb. Two-day-old, Kıvırcık breed, male a lamb was brought with the complaint of congenital swelling back to head, disability of standing and positioning the head. Together with the findings in anamnesis, unskinned, painless and fluctuated $6 \mathrm{~cm}$ diameter swelling on the occipital region was determined clinically, the swelling was extirpated under general anesthesia.

Because postoperative early time healing was not resulted, euthanasia of the case was performed. Meningocel and unilateral cerebral hypoplasia was diagnosed following the necropsy and histopathological investigations.
\end{abstract}

Key Words: Meningocele, unilateral cerebellar hypoplasia, lamb.

\section{Giriş}

Koyunlarda farklı sistemlere ait pek çok doğmasal anomali görülmektedir ${ }^{4,1,17}$. Kuzularda sinir sistemine ait genellikle mikroensefali, hidroensefali, hidrosefalus, hipomiyelinogenezis, serebellar hipoplazi veya aplazi, kranioşizis ve kranium bifidum, ataksia, meningosel, meningoensefalosel ve spina bifida patolojileri ile karşılaşılmaktadır ${ }^{4,7}$.

Meningosel, craniumun kemik yapisında ya da vertebraların laminasında kongenital şe- killenmiş bir defektten meninkslerin içi sıvı dolu bir kese şeklinde dișarıya fitıklaşması$\mathrm{d}^{7}{ }^{7,16,18}$. Craniumdaki fitıklaşma meninkslerle birlikte beyin dokusunu da içeriyorsa meningoensefalosel $^{1,4,18}$, eğer columna vertebraliste medulla spinalisi içeriyorsa meningomiyolosel (spina bifida) adını almaktadır ${ }^{4,18}$.

Nöroradyolojik görüntüleme yöntemlerinin gelişmesi, serebellar malformasyonların tanınma sıklığını arttırmıştır. İnsan hekimliğinde ender karşılaşılan unilateral serebellar hipoplazi (USH), serebellar hemisferlerin bir bölü-

1 Uludağ Üniversitesi Veteriner Fakültesi Cerrahi Anabilim Dalı, 16059, Bursa, TÜRKIYYE. hsalci@uludag.edu.tr

2 Uludağ Üniversitesi, Veteriner Fakültesi Patoloji Anabilim Dalı 16059, Bursa, TÜRKIYYE 
münün yokluğudur ${ }^{2}$. Bu malformasyonun serebellar dokunun edinsel destrüksiyonu ${ }^{9}$ veya genetik predispozisyonlar sonucu ${ }^{14}$ şekillendiği bildirilse de, etiyopatolojik açıklamalar yetersiz kalmıştır ${ }^{9}$.

Veteriner literatüründe USH tanısı bugüne kadar hiç rapor edilmemiștir. Sunulan bu olgu ile 2 günlük Kıvırcık ırkı, erkek bir kuzuda meningosel ve USH'nin klinik, radyolojik, cerrahi ve histopatolojik bulgularının rapor edilmesi amaçlanmıştır.

\section{Vaka Geçmişi}

Kıvırcık 1rk1, 2 günlük, erkek bir kuzu, kafasının arkasında derisiz kese şeklinde bir şişkinlik ve ayağa kalkamama şikayetiyle Uludağ Üniversitesi Veteriner Fakültesi Cerrahi Anabilim Dalı Klinikleri'ne getirildi. Hasta sahibi, kuzunun annenin bugüne kadarki ilk ve tek yavrusu olduğu, annede gebelik süresi esnasında herhangi bir hastalık şekillenmediği, babanın da sağlıklı olduğu ve ağıldaki diğer koyunlardan doğan kuzularında herhangi benzer ve farklı bir sorunla karşılaşmadığını bildirdi. Kuzunun annesini emdiği ancak kafasını normal pozisyonda tutamadı $\breve{g}_{1}$ belirtildi.

Genel muayenede, kuzunun vital parametreleri normaldi. Ancak ayakta destekle dahi uramamakta ve başını yan tutup, normal konuma getirememekteydi. Emme refleksi ve görme ve işitme duyusu vardı. İnspeksiyonda cranium'un oksipital bölgesinde yaklaşı $6 \mathrm{~cm}$ çap11, derisi olmayan bir șişkinlik görüldü (Şekil 1a). Kese şeklinde olduğu belirlenen şişkinlik fluktuasyon kıvamında ve ağrısız bir yapıdaydı. Kese yapısındaki şişkinlik kemik yapıda bulunan yaklaşı $0,5 \mathrm{~cm}$ çaplı bir defektten dışarı doğru protre olmuştu.

Radyolojik olarak lateral radyografide oksipital kemik üzerinde radyolusent bir defekt ve yumuşak doku opasitesinde homojen bir şișkinlik belirlendi (Şekil 1b). Ultrasonografik muayenede kese içerisinde yumuşak doku ekojenitesi görülmedi (beyincik dokusu) ve içerisinde sıvı ile dolu anekoik bir yap1 görüldü.

$\mathrm{Bu}$ bulgular temelinde olgunun meningosel veya meningoensafalosel olabileceği, hidrosefalus ya da parankimal agenezisin de bulunabileceği düşünüldü. Hasta sahibinin izni alınarak olgudaki bu şişkinliğin uzaklaștırılmasına karar verildi. Kuzunun genel anestezisi xylasine $\mathrm{HCl}(0.1 \mathrm{mg} / \mathrm{kg}$, im) ve ketamin $\mathrm{HCl}(4 \mathrm{mg} / \mathrm{kg}$, im) enjeksiyonlarıyla sağlandı. Rutin cerrahi hazırlık sonrasında şişkinlik deri bağlantısının bulunduğu dip kısımdan tekniğine uygun ensizyonla disseke edildi. Şişkinliğin dibine transfiksasyon ligatürü uygulandı ve kemikteki defekt kısmın bulunduğu yerden eksize edilerek uzaklaştırıld1. Takiben deri kapatıldı. Postoperatif 5 gün boyunca günde iki kez fluniksin meglumin $(1,1 \mathrm{mg} / \mathrm{kg}$, iv) ve penisilin G (10.000 IU/kg, im.) uygulanan hastanın 2 haftalık postoperatif bakım süreci sonunda klinik tabloda herhangi bir iyileşme şekillenmediği için hasta sahibinin izni ile dekapitasyon yapılarak ötanazisi gerçekleștirildi.
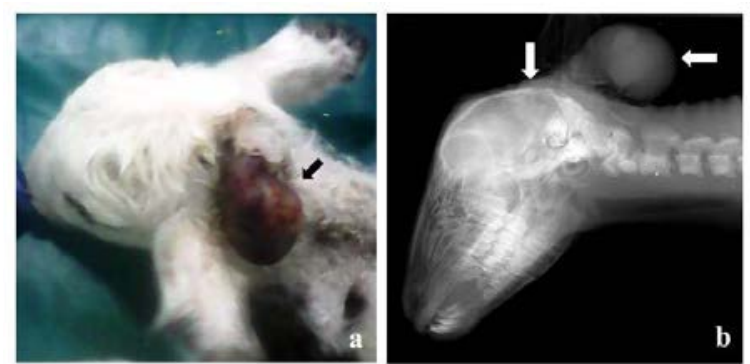

Şekil 1. a: Klinik olarak oksipital bölgedeki şişkinliğin (ok) görünümü, b: lateral radyografide craniumun kemik dokusundaki defekt (aşağı ok) ve şişkinliğin görünümü (sol ok).

Figure 1. a: Clinical apperance of the swelling on the occipital region (arrow), b: defect on the bone tissue of the cranium (dawn arrow) and apperance of the swelling (left arrow) in the lateral radiograph.

Craniumun makroskobik incelemesinde oksipital kemikte yaklaşık $0,5 \mathrm{~cm}$ 'lik bir defekt ve bu bölgede enfektif görünüm belirlendi (Şekil-2a). Kafatası açıldığında, beyincik üzerindeki meningeal dokunun kemik dokuya yapıştığı, yaklaşık $2 \mathrm{~cm}$ çaplı sert kıvamlı, kesit yüzünden irin gelen bir kitlenin şekillendiği görüldü (Șekil-2b). Beyinciğin sağ yarımının bir bölümü yıkımlanmıştı (Şekil-2c). Bu görünümü itibariyle makroskobik olarak USH tanısı konuldu.

Alınan doku örnekleri \%10'luk formaldehit tespiti sonrası rutin takip işlemlerinden geçirilerek parafine gömüldü ve 5 mikron kalınlığında kesitler alındı. Hazırlanan preparatlar hematoksilen\&eozin ile boyandı ve 1ş1k mikroskopta incelendi.

Kemik doku içerisinde şekillenmiş kitlenin mikroskobik incelemesinde, çevresi yoğun bağ doku ile sarılmış, merkezinde çoğunluğu nekrotik şiddetli nötrofil lökosit infiltrasyonları görüldü (Şekil-2e). Beyinciğin mikroskobik incelemesinde ise, ak maddede gliozis, purkinje 
hücrelerinde silinme ile nonpurulent meningitis dikkati çekti (Şekil-2f).

Kistik yapının mikroskobik incelemesinde; kitle duvarının fibrin, ödem ve çok sayıda nötrofil lökosit infiltrasyonlarından oluştuğu ve yer yer bakteri kümelerinin bulunduğu gözlendi. Hafif derecede yer yer organizasyon șekillendiği, bol miktarda kapillar damar varlığı dikkati çekti. Merkezi kısımlarda ise eozinofilik boyanma özelliği gösteren, fibrinden zengin proteinöz içeriğe rastlandı (Şekil-2d).

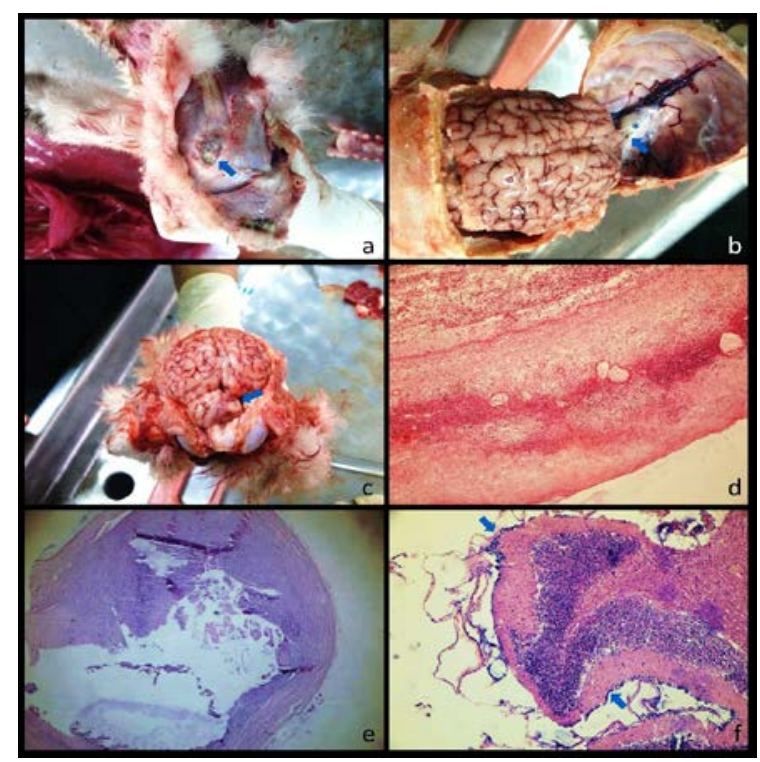

Şekil 2. Kafatasl, a: defekt bölgesinde irinleşme (ok), b: beyincik üzerindeki meninkslerin kafatasindaki defekt ile arasindaki bağlantı (ok) ve apse oluşumu (asteriks), c: sağ beyincik hemisferinde hipoplazi (ok), d: meningosel kesesi; şiddetli ödem, fibrin ve nötrofiller (H\&E, 40x), e: kafatasl defekt bölgesinde ssekillenen apse (H\&E, 40x), f: beyincik sağ hemisfer, nonpurulent meningitis (oklar), (H\&E, 40x).

Figure 2. Skull, a: pus in defect area (arrow), b: connection between meninges and defect of the skull (arrow) and abscess formation (asterix), c: right hemisphere hypoplasia of cerebellum (arrow), d: meningocele pouch; severe edema, fibrin and neutrophiles ( $H \& E$, $x 40$ ), e: abscess on the defect area of skull (H\&E, x40), $\mathrm{f}$ : right hemisphere of cerebellum; nonpurulent meningitis (arrows) (H\&E, $x 40$ ).

\section{Tartışma}

Yeni doğan kuzularda meningosel, meningoensefalosel, meningomiyelosel, hidrosefalus gibi birçok anomalilerle karşılaşılmış olup; en yaygın olarak hidrosefalus internusun görüldüğü literatürlerde bildirilmektedir ${ }^{4,71,16,18}$. Sunulan olgumuzun yapilan muayeneleri sonrasinda meningosel veya meningoensefalosel ile birlikte hidrosefalus ya da parankimal agenezisin olabileceği düșünülmüștür. Meningosel ve meningomiyelosel olguları intrauterin dönemde şekillenen serebrospinal sıvı basıncındaki artış nedenli olabilmektedir. Meningosel, meningoensefalosel ve meningomiyosel olgularına ilişkin raporlar bulunmasına rağmen ${ }^{1,3,4,7,12,16}$, meningosel ile birlikte USH patolojisini tanıdığ1mız olgumuz bugüne kadar kuzularda hiç rapor edilmemiştir ${ }^{13}$.

İnsanlarda serebellar hipoplazi, farklı hastalık tablolarıla gözlenmekte ve primer (malformatif, genetik) ve sekonder (distruptif, edinsel) lezyonlar olarak siniflandırılmaktadır ${ }^{13}$. USH ender gözlenen bir malformasyondur ${ }^{15}$ ve edinsel olarak bildirilse de bu tip patolojiler genetik predispozisyonlar sonucunda oluşmaktadır ${ }^{13}$. Anamnezde hasta sahibinin, anne ve babanın sağlıklı ve ağılındaki diğer hayvanlarda benzer bir problemin olmadığını bildirmesi, bizde anneye ait resesif bir genin meningosele yol açmış olabileceği ihtimalini düşündürmüştür. USH'nin ise meningosel sonucunda edinsel olarak şekillendiği tespit edilmiștir. Koyunlarda serebellar hipoplazilerin nedeni olarak intrafötal viral enfeksiyonlar düşünülmektedir ${ }^{8,10}$. Unilateral serebellar malformasyonlar bazen klinik bulgu göstermeksizin de şekillenebilmektedir ${ }^{5}$. Sunulan olgumuzun klinik muayenesinde görme, duyma ve koklama duyularının olduğu, emme refleksinin de varlığ rolojik olarak, kuzunun denge problemi olduğu ve ayağa kalkamadığı, başını kaldırıp sabit tutmakta zorlandığı görülmüştür.

İnsanlarda serebellar hipoplazi ileri görüntülü tan1 yöntemleri kullanılarak (magnetik rezonans inceleme ya da bilgisayarlı tomografi) tespit edilmektedir ${ }^{5}$. Ülkemizde veteriner fakültelerine bağlı hastanelerde ileri tanısal tetkiklerin kullanımı halen yaygın değildir. Bu nedenle olgumuzun tanısal yaklaşımında bu tetkiklerden yararlanılamamıştır.

Meningosel ve meningoensefalosel olgularında karşılaşılan kese hacmi ve kemikteki defekt küçük ise punksiyon ve aspirasyon sonrasında kesenin cerrahi olarak total rezeke edil- 
mesinin yeterli olduğ $\mathrm{u}^{1,3,7,11}$, kemik dokuda karşılaşılan defektin geniş olduğu durumlarda ise metal implant kullanarak defekt onarımının yapıldı̆̆1 ve prognozun iyi olduğu bildirilmiştir $^{1,7}$. Olgumuzda oksipital bölgedeki şişkinliğin genel anestezi total rezeksiyonu gerçekleştirilmiş ancak klinik bir iyileşmeyle karşılaşılmamıștır. Bu durumun nedeni olarak nekropside tanınan serebellumun unilateral hipoplastik oluşudur diyebiliriz.

Sonuç olarak meningosele sahip kuzularda operatif müdahaleler ile tam iyileşme sağlanabilmesi için edinsel olarak beyin ve diğer dokulara ait sekonder bir anomalinin olmamas1 gerektiği görülmüştür. Craniumun içerisindeki yumuşak dokular net olarak algılanamasa dahi, meningosel ve USH'nin ayırıcı tanısında klinik, radyolojik, ultrasonografik muayene ile cerrahi bulguların diagnostik ve prognostik açıdan önemli katkılar sağlayacağı söylenebilir.

\section{Kaynaklar}

1. Alkan, İ., Bakır, B., Dilek, F.H., Belge, A., 1995. İki Akkaraman kuzuda meningoensefalosel olgusu. Y.Y.Ü. Sağlık Bil. Derg., 1, 71-75.

2. Benbir, G., Kara, S., Yalcinkaya, B.C., Karhkaya, G., Tuysuz, B., Kocer, N., Yalcinkaya, C., 2011. Unilateral cerebellar hypoplasia with different clinical features. Cerebellum, 10, 49-60.

3. Blood, D.C., Rados Tits, O.M., 1990. Veterinary Medicine: A Textbook of the Diseases of Cattle, Sheep, Pigs, Goats, Horses. 7th ed, BailiereTindall, London.

4. Dennis, S.M., 1993. Congenital defects of sheep. Vet. Clin. North Am. Food Anim. Pract., 9, 203217.

5. Emlik, D., Kıreşi, D., Karabacakoğlu, A., Karaköse, S., 2002. Semptomsuz tek taraflı serebellar agenezi. Genel Tip Derg., 12, 109-112.

6. Erdogan, N., Kocakoc, E., Bekar, D., Ozturk, O., 2002. Unilateral absence of cerebellar hemisphere: a case report. Neuroradiology, 44, 49-51.

7. Ertürk, E., Samsar, E., 1978. Bir kuzuda doğmal1k spina bifida ve meningocele. Ank. Üniv. Vet. Fak. Derg., 25, 261-266.
8. Herder, V., Wohlsein, P., Peters, M., Hansmann, F., Baumgärtner, W., 2012. Salient lesions in domestic ruminants infected with the emerging so-called Schmallenberg virus in Germany. Vet. Pathol., 49, 588-591.

9. Johnsen, S.D., Tarby, T.J., Lewis, K.S., Bird, R., Prenger, E. 2002. Cerebellar infarction: an unrecognised complication of very low birthweight. $J$. Child. Neurol., 17, 320-324.

10. Nettleton, P.F., Willoughby, K., 2007. Border disease. In: Aitken, I.D. (Ed) Diseases of Sheep. 4th edition. Blackwell, UK, pp.119-126.

11. Özaydın, İ., Kılıç, E., Okumuş, Z., Cihan, M., 1995. 1992-1995 yılları arasında Kafkas Üniversitesi Veteriner Fakültesi Cerrahi Kliniği’ne getirilen buzağılardaki doğmasal anomali olguları. Vet. Cer. Derg., 1, 22-25.

12. Özaydın, İ., Okumuş, Z., Baran, V., Kılıç, E., 1996. Meningoselli bir morkaraman kuzuda kranioplasti. Kafkas Üniv. Vet. Fak. Derg., 2, 103109.

13. Poretti, A., Boltshauser, E., Doherty, D., 2014. Cerebellar hypoplasia: differential diagnosis and diagnostic approach. Am. J. Med. Genet. C. Semin. Med. Genet., 166, 211-226.

14. Poretti, A., Leventer, R.J., Cowan, F.M., Rutherford, M.A., Steinlin, M., Klein, A., Scheer, I., Huisman, T.A., Boltshauser, E., 2008. Cerebellar cleft: a form of prenatal cerebellar disruption. Neuropediatrics, 39, 106-112.

15. Poretti, A., Limperopoulos, C., Roulet-Perez, E., Wolf, N.I., Rauscher, C., Prayer, D., Muller, A., Weissert, M., Kotzaeridou, U., Du Plessis, A.J., Huisman, T.A., Boltshauser, E. 2010. Outcome of severe unilateral cerebellar hypoplasia. Dev. Med. Child. Neurol., 52, 718-724.

16. Sarma, B., Deka, K.N., Lahon, D.K., Pathak, S.C., 1993. Congenital meningocele in a bovine calf. A case report. Indian. Vet. J., 70: 67.

17. Schunk, K.L., 1992. Disorders of the Spinal Cord. In: Morgan, R.V. (Ed) Handbook of Small Animal Practice, 2nd Ed. Churchill Livingstone, New York, pp. 278.

18. Urman, H.K. 1983. Evcil Hayvanların Özel Patolojik Anatomisi. Ankara Üniversitesi Basımevi, Ankara. 